UDC 16

Ana BAZAC

\title{
THE THREE-TIER CORRECTIVE REASONING
}

\begin{abstract}
Written in honour of the late Academician Georg Brutian, the paper draws attention on one of the most special means of the transformative logic, the corrective argumentation, called here reasoning, that better emphasises the specific of arguments as such: that to inform semantically about the intention to arrive to certain conclusions. The corrective reasoning is that which reviews not only the validity of inferences, but also of the different types of premises lying at the basis of the theories people erect about every moment and aspect of life and reality. The corrective reasoning is the form of the capacity to critique the former judgements and has three tiers: the first - concluding that the former/existing theory was proven to be wrong; the second - gathering the arguments of alternative theories, and the third - focusing on the best/or even only in present the more economical alternative theory.

Every tier has more strata of reasoning whose result is the correction: the conclusion that 1) the old results (and focus on examples/situations), so the old theories require/directly send to their refutation, and 2) the conclusion suggests just some arguments of alternative theories. The corrective argumentation is not reduced to propositions, neither to syllogisms, but is constituted of the many relationships between statements.

From all the domains the corrective argumentation does manifest within and about, the scientific one was chose just because here the corrective approach is compulsory and its pattern - the most obvious. An epistemological analysis was deployed and it was demonstrated that the goal of the corrective reasoning is truth (in a certain concrete temporal interval) and the way to it involves the better understanding of the semantic level of language and its dependence on the real world.

Because the corrective reasoning is a question of daring and imagining new theories, the mechanism of this process was sketched by showing that consciousness has not only a passive face (that of representations) but always an active one too (the intention toward the external world), and by focusing on the logical forms as structures of thinking and their relationships with the external world "through the medium of" their internal consistence and coherence. In its turn, argumentation has in view both the formal model and substantial model of situations.

The specific of the corrective reasoning in science shows the difficulty of this endeavour and some deviations from this specific. The conclusion is that, indeed, the corrective reasoning is revolutionary.
\end{abstract}

Keywords: corrective reasoning/argumentation, science, scientific theories, truth, imagination, logical forms, conditions of validity, incorrect knowledge. 


\section{Introduction}

I intend to present a reasoning that is within the core of transformational logic: the corrective reasoning. In fact, it is about argumentation, considering not only the validity of inferences, but also the (changing) types of premises and the questioning/reviewing of their arguments/proofs; as a result of this reviewing, new premises are constituted and the old ones are no longer true, but only true in their temporal frame: and thus they became (historical) hypotheses whose conclusions are, obviously, no longer true.

Indeed, if logic contributes to the transformations within and of the world, it does this through its capacity to review and critique its former manifestations. And do not forget: logic is always propositional, "mental" or "explicit" (as Brutian has pointed, Brutian, 1998, p. 96), and not a question of unarticulated proof of the empirical facts. On the contrary, these empirical facts are viewed/ sensed and thus they have "corresponding images" - specific synapses leading to units of more or less coherent information - in the human mind. These units of information, their deployment and linking must be, however, expressed in words and judgements. The corrective reasoning/argumentation is the form of the capacity to critique the former judgements and has three tiers:

- the first - concluding that the former/existing theory was proven to be wrong,

- the second - gathering the arguments of alternative theories,

- and the third - focusing on the best/or even only in present the more economical alternative theory.
The corrective argumentation constitutes in the diachrony or process of confrontation of theories with reality, including with the theoretical refutations of their tenets, and accumulation of proofs of their falsity or incongruence.

Every tier has more strata of reasoning whose result is the correction: the conclusion that 1) the old results (and focus on examples/situations), so the old theories require/directly send to their refutation, and 2) the conclusion suggests/brings just some arguments of alternative theories (theories opposed to the old ones, and constructing systematically - with the theoretical instruments of scientific theories: arguments, verification, falsification, demonstration, experiments, all of them both real and virtual - the best or most economical alternative theory). Actually, every tier is like a Matrioshka doll, containing more propositions, different levels of arguments and their valuation: the biggest doll being that where the final conclusion of the correction, after the intermediary assessments, is constituted. The corrective argumentation is not reduced to propositions, neither to syllogisms, but is constituted of the many relationships between statements: it supposes the connecting of "simple" truths of propositions and syllogisms in order to configure a new truth/viewpoint about reality.

It's obvious that the pattern of corrective reasoning is realised in - and may be deduced from - both the common thinking and the scientific endeavour. In the first it is experienced in the practical process of learning through trial and error, or of falsification of prejudices, or of experiences in doing and thinking. And sometimes the correction arrives too late, when the better solution does no longer 
change the implacable course of things following the former decisions: then if people say aloud "I regret" (Bazac, 2016) - but many are not educated to think this, let alone to say - they can at least be happy that finally, though often in the final moment, they understood the right alternative as well as the necessity to correct one's position; but not this ethical analysis is intended here. Anyway, the regret shows that a corrective reasoning already has occurred.

Concerning the scientific endeavour, just its realm is where the pattern of corrective reasoning arises in the most obvious way. It does it through the epistemological analysis of the developed, sophisticated movement of thinking - illustrated in the best way by scientific theories.

\section{Epistemology of the corrective essence of scientific theories}

How does this pattern constitute? The ground is that the former theories prove to be more and more uncomfortable (denied by their consequences, falsified by experiences). Actually, the corrective argumentation is the result of and is doubling both the doubts concerning the old theories and the tensions between the tendency to keep them or to conceive of alternative theories: at the beginning, it advances only the possibility of these alternative theories. Consequently, the corrective argumentation is the sign of a crisis of knowledge and more, of the possibility of emergence of the novelty that ends the former crisis.

As we see, the problem of the pattern of corrective reasoning is one of epistemology (and one of the more important): and of epis- temology as conscious and systematic approach of the constitution and development of rational/scientific theories which represent the best understanding of the world in a space-temporal framework. This epistemology has developed in the $20^{\text {th }}$ century, after the agglomeration of scientific theories with certain and fruitful results. The analysis of these theories has put also the problem of their constitution, evolution and superseding. As we know, Thomas Kuhn with his theory of discontinuous scientific revolutions (1962) was one of the leading representatives of the evolutionary/historical epistemology: where the new paradigms correct/substitute the old ones grounding the "normal science", being thus the result and the sign of a deep corrective reasoning. Another representative was Karl Popper, whose process of falsification, being permanent, transforms the evolution of science into a continuous revision of theories (as in Toulmin, 1972) following the data/experiments falsifying their tenets. In fact, both these great thinkers have completed each other, coming into notice the different temporal and psychological aspects of the corrective reasoning.

3. What is it at stake in the corrective reasoning: the way to truth

The corrective argumentation is the gate toward imagination ${ }^{1}$, i.e. openness toward a

1 At the historical level, we can remember one of the first signs of corrective reasoning: that of the making of tools from stones or branches - whose first appearance did not suggest their functions as extension of man's abilities but only their external objectivity of eventually desired things - but imagined by humans as 
plurality of alternatives. Firstly, it only overturns the first theory and thus it seems that only one alternative would be possible: the negative form of the first theory. But then, during the first tier - the process of falsification of the former arguments - multiple paths are opening pushing people to reflect on challenging alternatives.

Indeed, in the corrective process one learns and arrives to the methodological conclusion that there are never only two alternatives (the former theory and its negation), but always multiple negations or, respecting the sides and nuances of the real problems, multiple paths to understand and solve them. Therefore, if logic is which "get you from A to B" - as Einstein said, while "imagination will take you everywhere", he added - the logic itself favours this overtaking, since it plays with possibilities: and I do not speak about the modals, but about the formula of reasoning, the mandatory consequences of the premises taking place in different times/realities.

The corrective reasoning once more emphasises the semantic level of language (Morris, 1938, pp. 21-28), drawing attention on the relations between the signs/phrases and their denotation/referent. Only from this standpoint of the relations between phrases and their referent do we speak about truth and false: or the criteria according to which we consider the phrases as true or false refer just to the relations between the phrases and their denotations. The truth value of a phrase is just the denotation / that what the phrase refers to / the significances of the phrase. Consequently, the reasoning - relationships between phrases and especially the corrective reasoning, have

protraction of their hands. Imagination itself was the result of a corrective reasoning. in view their informative value: the significances being true or false corresponding to the information the phrases provide. Certainly, it is always about the conditions - among whom the syntactic means too- when the significances are true: i.e. the significances are taken into account as true when they present the information in the enounced conditions. In other words, this is the illocutionary meaning, and phrases have their illocutionary potential resulted from the illocutionary rule of correspondence between the reality they have in view and their transparent intention to articulate this reality (Alston, 2000, pp. 5864).

The reasoning is a logical inference, where the inference is valid: according to the informative/semantic/illocutionary rule and value. The reasoning is that which develops the meanings of the words, and the words themselves: only by experimenting the logical inferences and their critique/confrontation with other inferences and the real state of things, one creates and becomes aware of new meanings, words and new aspects of reality.

But in this process, the difference between logical inferences and arguments does appear. The simple statement of a fact, as logical as it is/ as logically it is expressed, is not an argument: or, if we use a metaphorical synonymy, it is only an implicit argumentation. "It's winter and it's cold" or "Peter doubts Mary is there" have informative meaning about some facts and use the logical inferring, but they do not inform about the intention to use these phrases as support of certain conclusions. The arguments are just those inferences that inform semantically about the intention to arrive to certain conclusions. The words for, because, but, nevertheless, howev- 
er, at the same time, even though, almost, as much as etc. signal just this intention. Actually, these words cooperate to give the meaning of a phrase, meaning "claiming to give the orientation of the further dialogue" (Anscombre et Ducrot, 1976, p. 14). To argument is just to give the orientation toward a certain conclusion.

If in arguments the premises are considered true - even if they are presented as hypotheses (Anscombre et Ducrot, 1983) - it results that the conclusions must be true too: although the phrases - and more, the chains of phrases - are polyphonic, the arguments are blocks of phrases and significances which direct the results.

If so, then the understanding of the world follows an unceasing dialogue and confrontation between arguments. Each of them starting from different premises and orienting to different conclusions. The permanent revision of arguments is then normal: because there is not only about the confrontation of formal expressions, but also - and when all is told the confrontation of these formal expressions with the reality they intend to describe and transmit. The praxis that mediates this confrontation - the practical analysis of information resulted from the reaction and action relationships to and with the environment, and the correction of reactions and actions (including the representations about the world) according to this analysis/ the information resulted - supposes and includes just the confrontation between representations and arguments.

Thus, the corrective reasoning is the first human tool of the adaptation to environment, the inner condition of action relationships with this environment. Actually, the human logos as such and the human action - creating tools of action and transforming both the environment and the human being - intertwine and are interdependent, but the "banal" pattern of logic is the basis of the human character of all reactions.

As we know, the Greeks, Plato and Aristotle were somehow naïve: they seemed to presuppose that, since the logos and the ability to articulate it were/are the condition of humanity and since the logos meant/means to discern the truth from the false and to arrive to/choose the truth because only the truth is the sign of logos, if something is known (therefore, people have arrived to the truth) it is already (or at least virtually) realised as such and the positive consequences of this fact follow and are to shape the course of things: simply, people will assume the truth ${ }^{2}$, has thought Plato, while Aristotle has pointed that the incorrect statements and behaviour would be the result of opinions. Actually, this course is more complicated, and unfortunately it is not the result of the truth only (and nor can we emphasise it only from the emotions, since there is always a coexistence of reason and emotions). For this reason: nor can we conceive the corrective reasoning as occurring systematically only with an eye to the truth and its beneficial results. No, the corrective reasoning is only a means in man's concrete historical exploits. In rhetoric - and not only - intentional false corrective reasoning are

2 Actually, this standpoint corresponds to a very modern understanding of knowledge as such: we know only what is true - or, obviously, considered as true in a certain temporal and social frame - and assumed by the speaker; for us, the nonsense are only noise and we remove them from our consciousness. 
common, since the goal of rhetoric is to convince, and not to learn the truth.

From the multifarious manifestations of the corrective reasoning in the entire human life I chose that from the scientific theory. Here the conscious / intentional corrective reasoning is a compulsory demarche: otherwise the progress of knowledge does not take place. The second constraint is that in science the search for truth - and not for convincing and dominating - is compulsory as well: knowledge and its progress depend just on the proportion of true cognisance and ways to them. Consequently, the model of scientific argumentation might be taken as model of the corrective reasoning.

\section{The corrective reasoning and imagination}

The corrective reasoning is a question of daring - to doubt about the existing reasoning and its ordinariness - and of imagining alternative arguments. Some elements related to imagination and developed in the first half of the $20^{\text {th }}$ century - on the trail of Kant's constructivism - are useful for the understanding of the corrective reasoning. These elements appear in Husserl and (Sartre, 1936) and consist of new relations between the objective primordiality of the external world and the subjective consciousness of this world. Thus, the consciousness is not only representation i.e. the passive face of consciousness - but always active intention concerning the object/ world focused on. Because the awareness is always the awareness of something, the image of this something in the consciousness is different from the external something, and the intention of the awareness concerns the ex- ternal something, and not the image of this external something in the consciousness. However, the internal image - a marvellous invention of the consciousness - is already presenting us two things: the image as such the representation/the realisation of the representation (noesis, said Husserl) - and its meaning (noema, in Husserl's terms) relating the representation and the external object. The meaning is relational, and just through the permanent intended confrontation of the internal image to the external intended object the creativity of the consciousness is possible.

And certainly, this creativity - arisen from the intentionality of the awareness (Husserl) - has as means and steps the corrective reasoning.

Sartre and Merleau-Ponty too have taken over this standpoint of the active consciousness, overtaking the habitual Cartesian view of passive representations, and demonstrating that the image is not a simple contents of the consciousness, but the operation of the whole consciousness, they have shown that this operation is socially relational: the noemas are socially constructed (Bazac, 2008). If so, the articulation of the understanding of the world - the expression of logos - supposes the social confrontation of different reasoning/arguments and inevitably their correction.

\section{The logical form of the corrective reasoning}

Indeed, the concrete manifestation of imagination / the manner it manifests is the logical form. Certainly, both the previous and the present chapter do occupy with what we detect in the human mind / consciousness (here the distinction mind-consciousness is super- 
fluous): actually, some aspects of the World 2, of mental processes and facts, as Popper has named them. But without understanding these aspects the habit of reasoning and correcting one's reasoning cannot be grasped either.

Therefore, the logical form is a structure of thinking, a logical general reflecting or isomorphic with the infinite variety of real particulars. The form of thinking has constituted within the process of complication of the (human) reactions to environment and was "abstracted" in order to reflect and put order within the infinite contents of the real world (or to have the ability to grasp it). This process has entitled the old Greeks to observe that the logos of the world and that of humans are the same.

The subtext of this observation was the confidence into both the reasonability of the world and especially the reason/good sense as the most equally distributed among human beings, as later on has Descartes formulated. But what was the reason of this confidence? Just the common logical forms allowing people to think, to judge: and the fact that these forms were and are always verified.

How are they verified? Obviously, the transposition of the structures of thinking into structures of language - as we know, this transposition is mostly (but not entirely) the result of a didactic process of separation of naturally interdependent levels - supposes these two types of structures/levels. Sometimes they are mutually hindering themselves in the reflecting/coherent articulating of the coloured various states of affairs: either "we have no words" for what we are grasping and even understanding, or we have some words, including habits of inferences, but things are not clear for us, and we arrive to substitute the real grasping with words and descriptions and arguments.

Anyway, in order to understand the world, people endeavour three types of verification (which are certainly intertwined): first, they verify the process of thinking and, since they have "some knowledge of logical forms" (Dumitru, 2015, p. 13), i.e. they judge within inferences and consider their correctness as a reason of the correct understanding, they are aware of this level of logical forms and always meet again them; secondly, they know the words and are sensitive towards their significances (towards the nuances of different synonyms etc.), and therefore try to fit the words to their intentions and thinking; and thirdly, they verify the correspondence of their reasoning and expressing for their fellow humans with the real facts.

In fact, as we saw, the human beings are always positioned in a double situation: on the one hand, they act/think/speak/solve the problem, and on the other hand but at the same time, they are aware of their acting/thinking/speaking/solving: they speak using/trying to use the rights words for the given circumstance, they verify their inner inferences, and put face to face the given circumstance/the real things and their judgements and vocal discourses. It does seem that man is a corrective animal, does it?

The complexity formed by $n$ levels of reality as they are grasped by the human intentions and structures of thinking once more appears in the corrective reasoning as such. Here we find the counter-posing of the arguments to reality - and certainly, this moment has as a ground $n$ premises, experiences, arguments - and the clash between arguments, 
this clash itself corresponding to different layers/stages of the understanding and again having as a ground $n$ premises, experiences and counter-posing to reality, arguments. Thus, the corrective reasoning appears in front of the necessity to solve a new situation, when the former arguments/theories do no more correspond and the solving needs the exceeding of routine in reasoning and acting: the corrective reasoning is the sign of the creativity of the human beings.

The pattern of this Janus type complex reasoning is based on the constraint of validity and this constraint in its turn is based on that of necessity: it is absolutely necessary the new arguments be consistent and coherent, as the old ones were (towards the intellectual conditions of their time, of course). This means that the arguments can explain the "new"3 reality only if they meet (therefore, from the standpoint of logic) a three tier necessity ${ }^{4}$.

- The first tier, the logical necessity means that at the level of logical forms, the conclusions follow from the premises "without the need of any further additional as-

3 A new reality may be not only a new real object unnoticed before, but also an aspect grasped with new intellectual tools (theories, experiments, concepts, principles, criteria).

4 The three types of logical necessity - logical (in fact, formal), analytical, metaphysical - are from Dumitru. Fine has talked about metaphysical, natural and normative ("there are three distinct sources of necessity - the identity of things, the natural order and the normative order - and that each gives rise to its own peculiar form of necessity" (Fine, 2005)). I speak about logical, semantic/analytical and naturalist (as the principle of necessity to apply to the objects) and specific/natural. sumptions that might turn out to be wrong/false" (Ibid).

- The second tier, the semantic necessity means that to some specific meanings (which are the result of the intention of consciousness) some specific words/expressions do correspond: the meanings are here the most important. Therefore, from analytical standpoint, the semantic necessity means that the words and expressions have meanings which are not denied by the common (or scientific) intuition: the correct use of words is here the most important.

- The third tier is the naturalist necessity that means that there is always a final correspondence between the logical use of words and the (always changing) real state of affairs: or that there is always a criterion of satisfaction (as Tarski has considered even for formalised languages, and Fine has developed in "The Problem of De Re Modality" (Fine, 1989)) towards words and thoughts according to their relations with the real world ${ }^{5}$.

5 Or, as in the good comparison (Fine, 1989, p. 199): "The focus of the logical argument is on the intelligibility of a certain kind of expression. The question is whether there is any meaningful use for free variables within the scope of a modal operator. The focus of the metaphysical argument is on the intelligibility of a certain kind of idea. The question is whether it makes sense to say of an object that it necessarily fulfills a condition. One might say that in the one case we are concerned with the intelligibility of a certain kind of expression without regard of what it might express, while in the other case we are concerned with a cer- 
And for not divagate too much (to the discussion of what does "real" mean, but also of the normative approach of the real - the fact that the human subject sees the real from the standpoint of "the good"/perfection of reality according to the models historically created by man, but also according to the explicitly good for the human person - that meaning that there is also a normative necessity), one can note that, still from the standpoint of logic,

- one has arrived at a fourth tier of necessity, the metaphysical one, explaining the reason of the logical use of words - i.e. the primordiality of their meanings as they arise from the relationships with the "objects" cut up by the intentionality of consciousness - in the correspondence between the logical use of words and the identity of objects: or, differently put, in the care of the human consciousness for the grasping and logical treatment of the identity of objects. Kit Fine has shown that the logical forms too reflect the identity of objects: "if logical form can take account of the repeated occurrence of a sentence, it should also be able to take account of the repeated occurrence of an object" (Fine, Modality and Tense. Philosophical Papers, quoted in Dumitru, op.cit.: pp. 15-16), and thus the modality de re is intelligible. Therefore, we define the words (according to their meanings) and the analytical truths are the conclusions of the definitional truths according to their meanings; the definition is thus of the meanings, but this is tantamount to say that it is of the objects signified by

tain kind of idea without regard for how it might be expressed." the words: "the activities of specifying the meaning of a word and of stating what an object is are essentially the same; and hence each of them has an equal right to be regarded as a form of definition". Consequently, "The metaphysical necessity refers to the existence of objects in their identity: the necessity has its source in those objects which are the subject of the underlying essentialist claim... The metaphysically necessary truths can then be identified with the propositions which are true in virtue of the nature of all objects whatever" (Fine, 1994).

Finally, as it was mentioned and already implicated in the above note about the metaphysical identity, there are types of necessity which are beyond the logical criteria: normative necessity and specific necessity (that is the concrete manifestation of the naturalist necessity) in different sciences and standpoints of the different levels/layers of reality. "Neither form of necessity can be subsumed, defined or otherwise understood by reference to any other forms of necessity" (Fine, 2005).

This last criterion of necessity, that of the standpoints of the different levels/layers of reality and, certainly, of the sciences studying them, is which is tackled in this paper and it is suggested by those who has shown the complementary character of the formal criteria advanced by logics and the "worldly" criteria of the real life (Toulmin $2003^{6}$, but also Fine).

6 "But analyticity is one thing, formal validity is another; and neither of these is a universal criterion of necessity, still less of the soundness of our arguments", Toulmin, 2003, p. 134; "logic is a normative subjective, concerned with the appraisal of arguments and the recognition of their merits, one could hardly expect any- 
The logical forms allowing the validity of inferences - thus, the formal possibility of truth - are only the scaffolding of the meanings it relates, and relates in such a manner as they might correspond to the real objects (as they grasp the identity of objects). Technically speaking, the relationship between meanings (of words, formulas etc.) and objects is one of intelligibility, and not of truth, and the valid inferences relate intelligibility and truth: both the intelligible meanings and objects, and the clarification of the complex relationships between objects (obviously, reflected in words with meanings). As much, the validity of inferences/logical forms contains an entire history of clarifications (negations, corrections). Simply put and letting aside the logical necessity (the necessity of logical forms and their sine qua non character), the logical forms reflect and structure the real necessity (this means also, in philosophical language, the metaphysical necessity of identity): and the human beings are constitutively aware of these necessities and their interacting, and they seek to control this complex fact, and arrive to do this. Once more, this is the reason of the Greek idea of coincidence of the cosmic and human logos.

\section{The argumentation}

From the most popular types of argumentation - in mathematics and in the juridical

thing else", p. 173; it would be necessary "the reintroduction of historical, empirical and even-in a sense-anthropological considerations into the subject which philosophers had prided themselves on purifying, more than all other branches of philosophy, of any but a priori arguments", p. 234. realm - Toulmin (2003) has derived that to arrive to a valid argument means to combine the "quasi-geometrical" form of the logical inference and the proper procedures to a certain problem. However, this answer "creates a further problem for us: to see how and why proper procedure demands the adoption of simple geometrical shape, and how that shape guarantees in its turn the validity of our procedures. Supposing valid arguments can be cast in a geometrically tidy form, how does this help to make them any the more cogent?" (Ibid, p. 88)

Consequently, one has to unite the simple explanation of logical arguments - the game of logical inferences of conclusions from premises (the logical forms), and the procedural rules of these inferences - with the "field-dependence" of the criteria or standards of evaluation of the choice of arguments and words. The assessment of the validity of an argument (i.e. its consideration as correct/good) has in view both the formal model of situations - for example, "In any field, the conclusions that 'cannot' be the case are those we are obliged to rule out" (Ibid, pp. 33-34), namely, the negative conclusions do not suppose their opposite would be possible in the same case and in the same time; or for the formal model of possibility the conclusion "must 'have what it takes' in order to be entitled to genuine consideration in that context (Ibid, p. 34) - and the substantial one specific to domains and problems.

The authority of arguments arises, thus, from their scheme (Ibid, pp. 87-130): data, warrants, backing of warrants, correctness of syllogisms in the specific case, and types of conclusions (necessary or probable). The scheme always must be adapted to the do- 
mains/problems/cases, its weight depends on the substantial reasons/field the scheme is applied within; and the apparent complication of this scheme with the backing of warrants i.e. demonstration/argumentation of the "proofs" advanced in order to justify the initial claim and to draw to a valid conclusion, or demonstration of demonstrations, or the burden of proofs related to the reasons advanced by the claims which links the initial data - signifies that the argumentation is not a syllogism, but a system of syllogisms, $n$ syllogisms, as it was mentioned before: the argumentation deals not with propositions, but with statements. And that: even though the conclusion takes place in the register of possibility, the argumentation reflects the logic of necessity, the consciousness of the necessity of that conclusion raising the problem of possibility.

The formal model of argumentation is absolutely necessary: but "it is not a paradigm" (Ibid, p. 133). This emphasis is very important for the corrective argumentation. Not the correctness of only the syllogism is at stake, but the entire coherent articulation of many syllogisms, that supposes: that at the basis people exercises their capacity to differentiate the things, then to link them, in a selective manner, then to arrive to some conclusions, and then to revise and correct the entire cycle of reasoning. Only in this way do we meet with liable argumentation, backing our lives so as to understand the reasons and consequences of our actions.

\section{The corrective reasoning in science}

In science, the verification is permanent, never once for all, and thus the falsification
(Popper) is, as a matter of fact, only a manner of verification. Thus, in the course of time, it is possible that old theories, already falsified and proved invalid, be used as important elements for a state-of-the-art theory in a domain (as in the present biology, the holistic approach of Aristotle, see only Delbrück, 1971; Bastit, 2016).

The corrective reasoning in science arises when the truth of a theory - and we know from Aristotle that, in order to arrive to the truth in a certain domain and in a certain temporal interval, a theory presented by the master to the disciple must have and has only one solution, and secure, while the answers resulted from a controversy aiming to persuade might have two and have different types and degrees of possibility (probability) - is shaken by different material evidences of its historical character of plausibility. The corrective reasoning is thus the antidote to the perishability of the truth as such.

The problem is that the material evidences of a theory/of its falsification are not the result of a cold analysis observing all the procedural rules of reasoning and scientific research, nor are they the following of the neutral agglomeration of facts being self-evident to the whole scientific community. The scientific research is a social process and all its aspects depend on many socially constructed interests, including the one of the search for truth. As a consequence, as the first step of a scientific research and making of a theory begins with the putting of probable premises, as the corrective approach of the existing theories treats its elements from a social standpoint, i.e. from different social points of view.

If so, the scientific argumentation does no longer appear as a clear-cut phenomenon 
in the sky of independent thinking confronting "objective facts" and arriving to one-sided and simple truths, but just a permanent quarrel of different hypotheses related to the same fact as well as to different ones. As Popper has shown, every fact is preceded by a problem - actually, the fact is considered through the angle of a hypothesis questioning the present theory and the fact as such - and then the hypothesis itself is inquired confronting it with facts. If we do not put the hypothesis to the test of induction (to the test of the confrontation with facts - and do not forget, irrespective of our selection of facts, they are never simple and few), we transform the hypothesis, as well as we did with the former theories, into prejudices.

Yes, before we tack together the hypothesis - the abductive reasoning, as Peirce has theorised it - we have a "perceptual judgement" (an open wonder regarding the fact, i.e. the new face of the world through the lens of the fact) which is not the object of the logical and scientific analysis, it is outside criticism. Only the abductive reasoning constituted on the basis of perceptual judgements is the object of scientific inquiry, for this reason it is "the first step of scientific reasoning" (Peirce, 1958 , § 218), the only one type bringing a new idea (Peirce, 1932, § 96) and being put to the test of facts (induction: the experimental testing of the hypothesis, Peirce, 1958, $\S 206)$.

The specific logical steps of science are deduction and induction, just on the basis of the abduction that proceeds as a "circumstantial method" from "the humblest details just because of their individualizing attitude" (Carettini, 1988, 141): in opposition with the Galilean paradigm of "universalizing, ab- stracting, quantifying reason" and tending to eliminate the individual, the accidental (Ibid, pp. 140, 141). We infer by comparing homogenous facts and deducing general features, and then by comparing heterogeneous facts, and a group of homogenous or heterogeneous facts with a single one, an "accident": and we have either a given rule in order to back our reasoning, or it is selected from plausible but probable rules already existing in our universe of knowledge, or we create the rule and we have to test it with the facts which awakened our need to guess a new rule (Eco, 1988). Thus, in every moment of the scientific research we have to think in a hypothetical manner and to put this hypothetical manner to the test of facts (AB. the test of correspondence) and of the grounds of our knowledge and hypotheses (see also Reichertz, 2010).

There is also the test of coherence of different rational decisions to choose such or such argumentation and theory (see Thagard, 2000), but what is important is that the entire problem of logic is related to the external facts and that this relationship supposes a permanent adaptation of the diverse reasoning to these external facts and milieu: while this adaptation, as well as the logic "of syllogism" (we remember, the syllogism was/ meant the unification of words), reflect the constraints of the social: they are "language games" if I may use Wittgenstein's formula, reflecting both the empirical causality and the formal one. The universals of the scientific inquiries arise just from this intertwining. Professor Brutian was right: the logic of argumentation (the above-mentioned logical forms) is universal, but argumentation depends on domains and context (Brutian, 1998). 


\section{Two warnings of psychology}

a) If there is never a pure behaviour of emotions - and certainly never one of reasonableness alone -, since reason and feelings intertwine and, beyond the individual, there is always somewhere in the general social atmosphere the intuition or knowledge of the reasonable/logical solution, the scientific endeavour ought to surpass the random character of reasonable control over emotions. In science, one must be conscious about the necessity to free the quest for truth from emotions and interests external to the scientific research. Indeed, science means consciousness of movement/development/change, thus of the logic of critique of every cognisance: consciousness of its inner corrective strategy, consciousness of the absolute necessity of this strategy, consciousness of its inner correctible character, and certainly, consciousness of the corrective endeavour as a result of the social dialogue in narrow and large sense as well. In science, the individual is not an isolated entity.

The consciousness of the corrective strategy - of every human, of society, and of science - is the more important as it reflects and realises that this corrective approach pertains only to the living, and obviously, only the superior living, the humans have the awareness of this approach. Creation means permanent correction, for indeed, the living matter does not behave as a simple repetition of the laws of physics, and the human being even more "co-designs its existence" (Nadin, 2015 , p. 7). And finally, the importance of the consciousness of the corrective strategy derives from the human consciousness of time, better - of the human treatment of time, where anticipation and creativity intertwine (Nadin, 2015). The consciousness of one's own identity and situation helps people to control themselves - and concretely, to correct their former reasoning and points of view - or to master their own power (as Aristotle has observed in the Nicomachean Ethics, 1150a12 -13): in fact, to impose reason over passion.

b) The consciousness is not enough to correct - and consciously - a theory according to the truthful data existent in a certain interval. As there is an individual superficiality and simplification of the theories one adhere to - see for example the halo effect fallacy, where people have a cognitive dissonance, i.e. the consciousness that they do not know, then they "correct" this situation by inferring from a single aspect the general state of things, concretely from "a perceived single positive trait of a person the conclusion of a generally positive assessment of that person" (Grcic, 2008) - as there is a tendency to reduce/simplify theories about more complicated and "invisible" sides of reality.

\section{Finally, the examples related to science}

The classic ones are those summarised by Bertrand Russell (Russell 1950, pp. 73, 74, $75,78,80-81-82)$. The clash between the argument of authority and the scientific reasoning having $n$ proofs/data and backings, the theories of the Ages of Faith and those of the modern science are already well-known ${ }^{7}$.

7 Let mention only some ones as referred to in Russell: Miracles, many thousands of witches burned; "Men's sins were punished by pestilence and famine, by earthquake, flood, and fire"; "To suppose that there are human beings 
at the antipodes was heresy"; "When Benjamin Franklin invented the lightning-rod, the clergy, both in England and America, with the enthusiastic support of George III, condemned it as an impious attempt to defeat the will of God"; "Although we are taught the Copernican astronomy in our textbooks, it has not yet penetrated to our religion or our morals, and has not even succeeded in destroying belief in astrology. People still think that the Divine Plan has special reference to human beings, and that a special Providence not only looks after the good, but also punishes the wicked"; "It was only very slowly and reluctantly that the church sanctioned the dissection of corpses in connection with the study of medicine. The pioneer in dissection was Vesalius, who was Court physician to the Emperor Charles V. His medical skill led the Emperor to protect him, but after the Emperor was dead he got into trouble"; "It is odd that modern men, who are aware of what science has done in the way of bringing new knowledge and altering the conditions of social life, should still be willing to accept the authority of texts embodying the outlook of very ancient and very ignorant pastoral or agricultural tribes"; "There are logical difficulties in the notion of Sin. We are told that Sin consists in disobedience to God's commands, but we are also told that God is omnipotent. If He is, nothing contrary to His will can occur; therefore when the sinner disobeys His commands, He must have intended this to happen. St. Augustine boldly accepts this view, and asserts that men are led to sin by a blindness with which God afflicts them. But most theologians, in modern times, have felt that, if God causes men to sin, it is not fair to send them to hell for what they cannot help. We are told that sin consists in acting contrary to God's will. This, however, does not get rid of the difficulty. Those who, like Spinoza, take God's omnipotence seriously, deduce that there
People have corrected the old theories having as argument the authority of Holy Scriptures of all the religions, and, though this process of superseding was painful and long, they have arrived to theories having as support the scientific inquiry of phenomena. (And, inherently, absurdities are found in great philosophers too - such as, in Plato, that "men who do not pursue wisdom in this life will be born again as women", or, in Aristotle, that "the blood of females is blacker than that of males; that the pig is the only animal liable to measles; that an elephant suffering from insomnia should have its shoulders rubbed with salt, olive oil, and warm water...that women have fewer teeth than men, and so on" - but "Commentators on great philosophers always politely ignore their silly remarks" (Ibid, p. 99).

But there are many examples in the science of the last 66 years after Russell's book, which show the difficulty to correct the scientific theories. The causes of this difficulty may be categorised: as causes arising from the extra-scientific domains (political, economical, cultural, ideological), and as causes inherent to the process of knowledge itself. The latter manifest as:

- the avoiding of the definition of concepts used (Russell, 1950, pp. 92-99: theories about the human nature without defining

can be no such thing as sin. This leads to frightful results"; "As soon as we abandon our own reason, and are content to rely upon authority, there is no end to our troubles. Whose authority? The Old Testament? The New Testament? The Koran? In practice, people choose the book considered sacred by the community in which they are born, and out of that book they choose the parts they like, ignoring the others". 
it; pp. 99-101: belief in 'nature' and 'what is natural'; etc.);

- the unclear definitions putting the functional analysis in both the physical and social sciences endeavour in an embarrassing situation: if there is a lack of empirical objective criteria, absolutely necessary for "precise objectively testable scientific assertions", so only if the concepts are ( $\mathrm{AB}$, i.e. consciously) "relativised", the explanations are valid and allowing predictions irrespective of the domain supposing laws or only tendencies (Hempel, 1965, p. 324);

- the concomitant use of concepts in different registers and their reciprocal substitution;

- the separation of formal correctness from the material one, and the ignorance of one of them, as Aristotle has shown long ago in his Analytics;

- in its turn, the material correctness is depending on the material tools the researchers use in order to measure and to "view"/perceive reality, and this material condition of correctness is too wellknown as to stop on it. But see only the dependence of scientific research on IT, the omnipotent instrument that mediates our understanding of the world: a recent study (Eklund et al. 2016, corrected for alleviate and at the same time make more precise two phrases, but "These errors do not affect the conclusions of the article. The online version has been corrected") has proved that the fMRI (Functional Magnetic Resonance Imaging) machine, providing an image of the brain and not the functioning in real time, and more, an image interpreted by a computer pro- gramme, was and is depending on the quality of the software programme. And when this quality is improved in order to eliminate the errors made by the former programme, it is necessary to review all the studies elaborated with the former programme. Two epistemological problems results from this situation: one is the necessity to repeat the experiments - including with different means - in order to validate them; the repetition of experiments/studies is compulsory for the accuracy of the scientific knowledge; and certainly, the necessity to create new (theoretical and practical) instruments of experiments and their validation; the other one - is the necessity to do away with the extra-scientific impediments to make and validate scientific experiments: the prohibitive costs of experiments - when today the states fund the tireless hunger of the military-industrial complex and wars - and the privatised scientific research (of companies that search for the immediate favourable costs-benefits formula) must be annulled in a new philosophy of the scientific research;

- another source of slow correcting is the avoiding of the empirical observation "thinking that you know when in fact you don't" (Russell, 1950, p. 103) and, once more, the avoiding of correct verification/falsification through sufficient experiments and concluding data;

- another one - is the avoiding of criticisms from the standpoint of other/opposed theories (Ibid, pp. 105-106; Popper, 1995). And certainly, the main cause of this avoiding is not technical, nor does it pertain to the psychology of researchers, but 
is the dependence on the social-political constraints of the scientific research: see only the conflict of interests of the researchers paid by concerns like Monsanto in order to justify the healthy results of the use of their products;

- the inertia of the use of old premises - already demonstrated as false -: just because the premises are based on tacit scientific and social/political presumptions which are believed to be proper to the general atmosphere of ideas, and thus more "academic";

- the low flexibility of the researchers' model of scientific approach; indeed, we should be critical not only about the premises, but also about what occurs in every moment of the research: as we know that the "lab research" has in view cut conditions/ideal conditions, as we have to exercise our attention to the changes related to every part of the scientific pattern; because what is the most important is not the accommodation to the basic hypothesis we started from, but the telos of the concrete research, or its ultimate reason: like the prices of the works of art which are the result not of the starting price or of the evaluation (both these premises are "lab/ideal conditions", with all the criteria included), but of the phenomena occurred later, when the "subjective" facts as the interest of persons and institutions and the sums allocated by them appear.

These few aspects should make us careful of the danger of "dogmatism" (Russell, in Preface), whose "growth", though grasped by lucid minds in the mid-century, is nowadays geometrical: the neo-liberal turn of modernity tends to impose superficiality, rather the incapacity to articulate the "why" of things ("the wherefore and the cause", said Aristotle, Metaphysics, 1, 981a1), (and "when adults fall back to the primitive causal schema and overextend it beyond the realm of mechanical causation, misconceptions are bound to occur" (Chen, 2015, p. 21), the relativisation of meanings, the incapacity to understand the difference between evil and good, and all of these turns are but a burden with ugly consequences for the logical thinking. Then what can we say about the corrective capacity of this logic?

\section{Instead of conclusions}

The corrective reasoning is always revolutionary: it changes the former theories their presumptions, demonstrations, steps and thus it erases the common impression that the logical forms/ the logic of argumentation or demonstration would be always cold and separated from the exuberant ontological diversity and possibilities of human points of view. Yes, the difficulty to see, to grasp and to understand seems as if the cold forms would lead to conformist manners of thinking: or as if their habit is that of fixing and reducing, impoverishing the infinite profusion of levels of reality and moments of their human understanding. In effect, the logical forms and the logic of argumentation are only means, so tools, of the understanding of the world and they follow the variety and wealth of its levels, moments and problems. People do understand when the logical tools are used in a non-logical way, and if they blame the logic and seem to be tired of so many arguments, it is not because of their turn toward an 
illogical status - though the rulers tend to determine this turn - that would oppose to reasonable arguments, but just because they are thirsty of logic, of accuracy, of precision. They feel that just the lack of logic, of accuracy, of precision does erase the infinite richness they could enjoy humanly.

The guilt of the illogical attitudes of people is then not the powerlessness of logic, but of the domination-submission relations which instrumentalise the logic, as they do with all the human features and instruments.

And let me mention that the power of the corrective reasoning (and attitudes) is shown by one of the most interesting forms of human practice: the fables, which are not simple lessons abstracted from tales, but demonstrations of the corrective characteristic of humans. Let me remind two old Armenian fables, written by Mkhithar Goch in the $12^{\text {th }}$ century: 1) "The fig tree was asked: 'Why you bend your branches so much to earth?' It answered: 'I have many enemies and I lower myself for they do not break my branches. Before one climbs on me, I reassure them and the enemies forget their malice'...; 2) "A foolish man badly hit a jujube tree, taking it as a blackberry. The tree became angry and said: ' $\mathrm{O}$, cruel man, one must recognise the plant according to its fruits, not according to its appearance'... (Deux...2006, pp. 16, 21).

The corrective reasoning has a holistic perspective. It takes account of all the tiers and aspects of a problem and its alternative theories, and this means that when all is told the logic of arguments cannot be opposed to the ethical scruples of peoples: the logic of arguments is for the sake of the Good, as Aristotle has considered and, later on the Stoics (Di Vita, 2016).

\section{REFERENCES}

Alston, W.P. (2000). Illocutionary Acts and Sentence Meaning, Ithaca: Cornell University Press.

Anscombre, J.-C., \& Ducrot, O. (1976). L'argumentation dans la langue. Langages, 10(42), 5-27.

Anscombre, J.-C., \& Ducrot, O. (1983). L'argumentation dans la langue. Bruxelles : Pierre Mardaga éditeur.

Aristotle. (2000). Nicomachean Ethics. (R. Crisps, Ed., \& Trans.) Cambridge, UK: Cambridge University Press, 150a12-13.

Bastit, M. (2016). La science aristotélicienne des animaux et la biologie contemporaine: d' Empédocle et Démocrite à Aristote. Noema, XV, 195-214.

Bazac, A. (2008). Sur l'imagination chez Merleau-Ponty et Bachelard. Analele Universităţii din Craiova, Seria Filosofie, nr. 22 (2), 19-48.

Bazac, A. (2016). The regret. Egophobia, 46, 14 June 2016, http://egophobia.ro/?p=11243.

Brutian, G. (1998). Logic, Language and Argumentation in Projection of Philosophical Knowledge. Armenian Library of Calouste Gulbenkian Foundation. Lisbon: Printed by Grafica De Coimbra, Ltd.

Carettini, G.P. (1988). Peirce, Holmes, Popper. In E. Umberto, \& T. Sebeok (Ed.) (1983) The Sign of Three: Dupin, Holmes, Peirce (pp. 135-153). Bloomington and Indianapolis: Indiana University Press.

Chen X. (2015). The Emergence and Development of Causal Representations. In 
L. Magnani et al. Philosophy and Cognitive Science II, Studies in Applied Philosophy, Epistemology and Rational Ethics. Switzerland: Springer International Publishing, 21-34.

Delbrück, M. (1971). Aristotle-totle-totle" in "Of Microbes and Life. (J. Monod, \& E. Borek, Eds.) New York: Columbia University Press, 50-55.

Deux fabulistes arméniens du Moyen Âge: Mkhithar Goch, Vardan Ayguéktsi, À la mémoire des arménistes français Jean Saint-Martin (1731-1832) et Frédéric Macler (1869-1938), Rédacteur Gohar Grigorian, Erévan: Éditions Nahapet.

Di Vita, N. (2016). Il logos tra filosofia e vita. Una nota sullo stroicismo antico. Meta: Research in Hermeneutics, Phenomenology and Practical Philosophy, Vol. VIII, June, 121-142.

Dumitru, M. (2015). Logical Form. In Cătălin Vasilescu, Maria-Luisa Flonta, Ioana Crăciun (Eds.) On Form and Pattern (pp. 11-16). București: Editura Academiei Române.

Eklund, A., Nichols, T.E., \& Knutsson, H. (2016). Cluster failure: Why fMRI inferences for spatial extent have inflated false-positive rates. Proceedings of the National Academy of Sciences of the USA 113(28).

DOI: 10.1073/pnas.1602413113.

Eco, U. (1988). Horns, Hooves, Insteps: Some Hypotheses on Three Types of Abduction. In E. Umberto, \& T.A. Sebeok (Eds.) (1983), The Sign of Three: Dupin, Holmes, Peirce (198220). Bloomington and Indianapolis: Indiana University Press.
Fine, K. (1994). Essence and Modality. Philosophical Perspectives, 8, 1-16.

Fine, K. (1989). The Problem of De Re Modality. In J. Almog, J. Perry, H. Wettstein (Eds.), Themes from Kaplan (197-272). New York, Oxford: Oxford University Press (reprinted in Modality and Tense: Philosophical Papers. Oxford: Clarendon Press 2005).

Fine, K. (2005). The Varieties of Necessity. In Modality and Tense: Philosophical Papers. Oxford: Clarendon Press. http://philosophy.fas.nyu.edu/object/ kitfine.

Grcic, J. (2008). The Halo Effect Fallacy. ELogos, Electronic Journal for Philosophy, 1-6.

Hempel, C.G. (1965). The Logic of Functional Analysis. In Hempel, (1959) Aspects of Scientific Explanation and Other Essays in the Philosophy of Science (pp. 297-330), New York: The Free Press; London: CollierMacmillan Lmd.

Morris, Ch.W. (1938). Foundations of the Theory of Signs. International Encyclopedia of Unified Science, I(2). Chicago: The University of Chicago Press.

Nadin, M. (2015). Anticipation and Creation. In Libertas Mathematica (new series), 35(2), 1-16.

Peirce, Ch.S. (1932). Collected Papers of Charles Sanders Peirce. (Ch. Hartshorne, P. Weiss, \& A.W. Burks, Eds.), Vol. 2, Cambridge, Massachusetts: Harvard University Press.

Peirce, Ch.S. (1958). Collected Papers of Charles Sanders Peirce. (A.W. 
Burks, Ed.), Vol. 7, Cambridge, Massachusetts: Harvard University Press.

Popper, K. (1994). The Myth of the Framework: In defence of Science and Rationality, (1965; 1986). (M.A. Notturno, Ed.), Abingdon, New York: Routledge.

Reichertz, J. (2010). Abduction: The Logic of Discovery of Grounded Theory. FQS Forum: Qualitative Social Research/Sozialforschung, 11(1), Art. 13.

Russell, B. (1950). An Outline of Intellectual Rubbish. In Russell, Unpopular Essays (pp. 71-111), New York: Simon
\& Schuster.

Sartre, J.-P. (1936). L'imagination, Paris: F. Alcan.

Thagard, P. (2000). Coherence in Thought and Action. Cambridge, Massachussets, London: MIT Press.

Toulmin, S.E. (2003). The Uses of Argument (1958). Updated Edition, Cambridge, New York: Cambridge University Press.

Toulmin, S.E. (1977). Human Understanding: The Collective Use and Evolution of Concepts. (1972), Princeton: Princeton University Press. 